\title{
AN EMERGING, NEGLECTED AND UNDERESTIMATED ZOONOTIC PARASITIC OCULAR INFESTATION: A COMPREHENSIVE REVIEW ON THELAZIASIS
}

\author{
Rajeshwar Reddy Kasarla, ${ }^{1}$ Shristi Raut Adhikari, ${ }^{1}$ Kripa Ghimire, ${ }^{2}$ Laxmi Pathak $^{3}$
}

\begin{abstract}
Human thelaziasis is an emerging insect-borne zoonotic ocular parasitic infestation, occur more commonly in rural communities with poor living and low socioeconomic living, and mainly affects the children and old age people, where humans live in close proximity with animals. Human thelaziasis is caused by both Thelazia callipaeda and Thelazia californiensis. T. callipaeda lives under the eye lids, nictitating membranes, orbit, conjunctival sac, lachrymal glands, and lachrymal ducts of cats, dogs, rabbits, horses, cattle, deer, badgers, monkeys, wolves, foxes (definitive hosts) and man being an accidental host. The vectors (intermediate hosts) are non-biting, tear-seeking, diptera flies of family Drosophilidae (fruit flies) Phortica variegata, which feeds on tears of their definitive hosts, including humans. Clinical manifestations include conjunctivitis, lachrymation, itching or pain with foreign body sensation, epiphora, follicular hypertrophy, and less often with severe signs and symptoms such as keratitis, photophobia, ectropion, corneal opacities (due to the migration of worm across the cornea), floaters within the eye chamber leading to visual impairment/blindness. The knowledge and scientific information on human thelaziasis is still unknown or relatively limited to many ophthalmologists and clinicians, and received little attention; hence this comprehensive review of human thelaziasis, is undertaken to highlight its importance and further research.
\end{abstract}

\section{KEYWORDS}

Ocular infestation, Thelaziasis, Thelazia callipaeda, Zoonotic.

1. Department of Microbiology, Universal College of Medical Sciences, Bhairahawa, Nepal

2. Department of Microbiology, Gandaki Medical College, Pokhara, Nepal

3. Department of Anaesthesiology and Critical Care Medicine, Universal College of Medical Sciences, Bhairahawa, Nepal

DOI: https://doi.org/10.3126/jucms.v9i02.42020

For correspondence

Dr. Rajeshwar Reddy Kasarla

Department of Microbiology

Universal College of Medical Sciences

Bhairahawa, Nepal

Email: reddysir4861@gmail.com 


\section{INTRODUCTION}

The ocular parasitic infestations by protozoan, helminthic, and some ectoparasites pose a critical threat in healthcare. Thelaziasis is one such emerging vector-borne zoonotic ocular parasitic infestation, occur more commonly in rural communities with poor living and low socioeconomic standards, and mainly affects children and the elderly, where humans live in close proximity with animals. ${ }^{1}$ It is caused by a helminthic spirurid nematode of the genus Thelazia, a veterinary parasite. Over 16 Thelazia species such as $T$. callipaeda (Oriental eye worm), T. californiensis (California eye worm), T. gulosa (Cattle eye worm), T. lacrymalis (parasitizes only horses), T. rhodesi (In cattle), T. leesei, T. alfortensis, T. skrjabini, T. ershowi, T. bubalis, T. anolabiata have been reported causing ocular infestations in animals. ${ }^{1}$ Human thelaziasis is caused by both $T$. callipaeda and $T$. californiensis. Human thelaziasis by $T$. californiensis is extremely rare and mostly believed to be accidental. ${ }^{2}$ The knowledge and scientific information on human thelaziasis is still unknown or limited to many ophthalmologists and clinicians, and received little attention; hence this comprehensive review of human thelaziasis, is undertaken to highlight its importance and further research.

\section{HABITAT}

T. callipaeda lives under the eye lids, nictitating membranes, orbit, conjunctival sac, lachrymal glands, and lachrymal ducts of cats, dogs, rabbits, horses, cattle, deer, badgers, monkeys, wolves, foxes (definitive hosts) and man being an accidental host. The adult females are ovo-viviparous and release embryonated eggs or first-stage larvae (L1) into lachrymal secretions (tears). ${ }^{4}$

\section{MORPHOLOGY}

T. callipaeda adult worms are thin, thread-like, elongated, cylindrical, and creamy to milky white (Fig 1). ${ }^{4}$ Male worms measure 4.5 to $13 \mathrm{~mm} \times 0.25-0.75 \mathrm{~mm}$ and females $6.2-17 \mathrm{~mm}$ x 0.3-0.85 mm. In both sexes, the mouth opening has a hexagonal profile. ${ }^{4}$ The female worm has a transversely striated cuticle, a pair of prominent cephalic extensions at the anterior end, protruding forward and a rectangular buccal cavity without suckers and teeth. The long muscular esophagus is about $0.6 \mathrm{~mm}$ in length with a normal and distinct esophago-intestinal junction. A simple, tubular intestine extended up to the posterior end, with anal opening at the caudal end. The reproductive system is well distinguished containing mature embryonated eggs in proximal uterus and the first-stage larvae (L1) in distal uterus. ${ }^{4}$ The male worm possesses similar buccal cavity but distinct esophagealintestinal junction and characteristic curved tail end with shorter spicule with pre- and post-cloacal papillae. On the mouth opening of male T. callipaeda, two large head papillae, distinct from the cephalic papillae were observed, that were absent in the females.

Morphological differentiation between $T$. callipaeda and $T$. californiensis is based on the numbers of pre- and post-cloacal papillae in the male and the position of the vulva in the female. In general, the male T. callipaeda worm has 8-10 pairs of precloacal papillae and five pairs of post-cloacal papillae, whereas the male T. californiensis worm has 6-7 pairs of precloacal papillae and three pairs of post-cloacal papillae. The vulva is anterior to the esophago-intestinal junction in $T$. callipaeda and this differentiates from T. californiensis as the later's vulval opening is posterior to the esophago-intestinal junction. $^{4}$

The embryonated eggs are oval shaped, thin shelled, when freshly laid, measuring 54-60 $\mu \mathrm{m} \times 34-37 \mu \mathrm{m} .{ }^{4}$

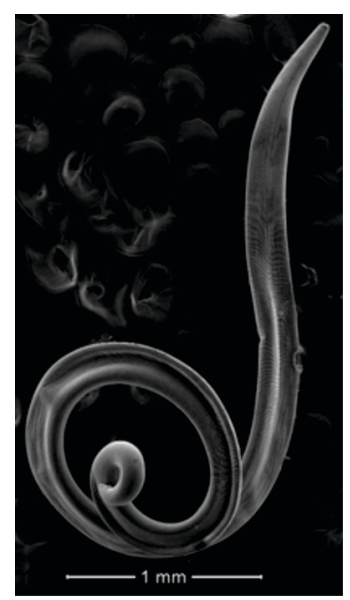

Fig 1. Thelazia callipaeda adult worm ${ }^{50}$

\section{THE INSECT VECTOR}

The insect vectors (intermediate hosts) are non-biting, tearseeking (secretophagous), diptera flies of family Drosophilidae (fruit flies) Phortica variegate (Fig 2a) (formerly Amiota variegata, recently taxonomically reclassified as Phortica variegate), and Phortica okadai, which feeds on tears (lachrymal secretions) of their definitive hosts, including humans. ${ }^{5}$ Phortica spp. display a zoophilic behavior, i.e., they feed on ocular secretions of animals and humans in addition to feeding on fruits and on fermenting tree sap. Phortica variegate and Phortica okadai are the primary intermediate hosts for T. callipaeda. Interestingly, only males of $P$. variegata were found to be infected with $T$. callipaeda under natural conditions. It has been found that the Musca domestica (common fly) is not a vector of T. callipaeda. ${ }^{1,4,6}$ Fannia spp. such as Fannia benjamini (canyon fly) and $F$. canicularis (Fig 2b) (lesser house fly), are the intermediate 
hosts for T. californiensis, while Musca autumnalis (face fly) is the intermediate host for T. gulosa. ${ }^{1,4}$
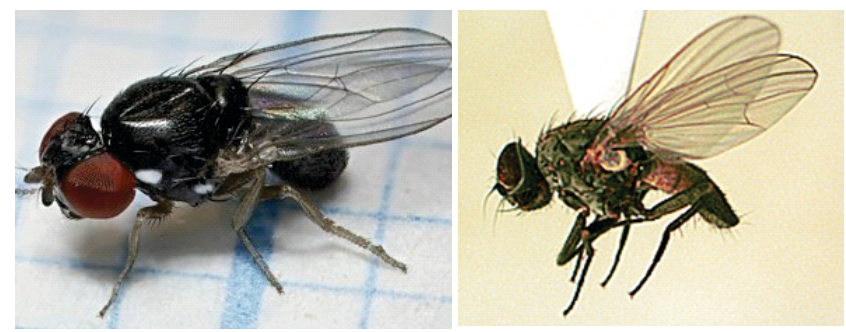

Fig 2. The intermediate host ${ }^{50}$ a) Phortica variegate (Fruit fly) b) Fannia canicularis

\section{LIFE CYCLE}

Adult parasite resides in the conjunctival sac of humans or animals (definitive host) where ovoviviparous females release first stage larvae (L1). En-sheathed L1 larvae are ingested by the fruit fly (intermediate host) while feeding lachrymal secretions (tears). Once inside the gut of the fly, the eggs hatch out and release L1 larvae, which is ex-sheathed and penetrate the gut wall, and invade various tissues such as hemocoel, fat body, testes, or egg follicles, where they develop into thirdstage larvae (L3). The larvae break out from these areas and migrate to the fly's mouthparts, and transmitted to the eyes of definitive hosts, when the fly feeds on the tears. The larvae invade the conjunctival sac, and pre-bulbar tear film and become adults through a fourth-stage larvae (L4), after about a month and two additional molts. Thus, the life cycle continues (Fig 3). ${ }^{1,4}$

The L1 larvae of Thelazia are very short-lived in the lachrymal secretions, only surviving few hours, and transmission depends upon the continuous presence of the vectors. For this reason, thelaziasis has a seasonal occurrence according to the seasonality of the intermediate hosts. ${ }^{4}$

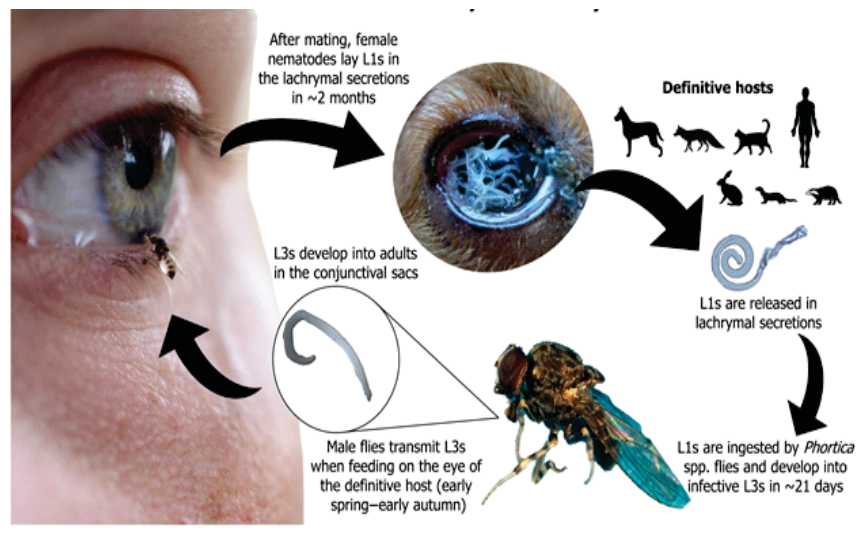

Fig 3. Life cycle of Thelazia callipaeda ${ }^{51}$

\section{EPIDEMIOLOGY}

T. callipaeda is prevalent in wide range of geography from tropical (Indonesia) and subtropical (Japan) to temperate (Russia). T. callipaeda requires mountainous environment for their biological cycle and survival. Among the Thelazia species, T. callipaeda has the widest spectrum of hosts. T. callipaeda has been reported from Asia and Europe and is prevalent in dogs, cats, and humans in Russia, China, Korea, Myanmar, Japan, Indonesia, Thailand, Taiwan, and India. T. californiensis prevalent in California (particularly in the Sierra Nevada mountains), and Western USA. ${ }^{1,4}$ Thelazia gulosa is widespread across Asia, Europe, North America and Australia. ${ }^{7}$ Human thelaziosis occurs mostly in rural communities with poor socio economic living, and mainly affects the children and old age people. ${ }^{1}$ In 1910, Railliet and Henry first described the arthropod- borne zoonosis by a nematode Thelazia callipaeda. ${ }^{8}$ The first report of human thelaziasis was from Beijing, China, subsequently cases increased in China, ${ }^{9}$ the Soviet Union, ${ }^{10}$ Indonesia, ${ }^{11}$ Thailand, ${ }^{12}$ India, ${ }^{13}$ Taiwan, ${ }^{14,15}$ Japan, ${ }^{16}$ and Korea. ${ }^{17}$ Human infection by $T$. callipaeda was reported from Europe in the area where canine thelaziasis were common. ${ }^{1,4}$ Over 250 cases of T. callipaeda have been reported in medical literature with maximum number of cases from China, Japan, India, Russia, Thailand, and Korea. T. gulosa (the cattle eye worm) was reported to cause human thelaziasis from North America.

\section{PATHOGENESIS AND CLINICAL MANIFESTATIONS}

Both the larval stages and adult worms of T. callipaeda, and rearely T. californiensis cause clinical manifestations such as exudative conjunctivitis, excessive watering (lachrymation), itching or pain with foreign body sensation, epiphora, follicular hypertrophy, and less often with severe signs and symptoms such as keratitis, photophobia, ectropion, corneal opacities (due to the migration of worm across the cornea), floaters within the eye chamber leading to visual impairment/blindness (Fig 4). ${ }^{18-20}$ It may also lead to the paralysis of the muscles of lower eye lid. In addition, the presence of nematodes causes infants to rub their eyes, and symptoms become more serious upon secondary bacterial infections with bacteria. ${ }^{4,8,18,19}$ Since the adult worm is larger than the eye, it can be noticed at an early stage, mostly in the conjunctival sac or medial or lateral canthus of the eye. ${ }^{19}$
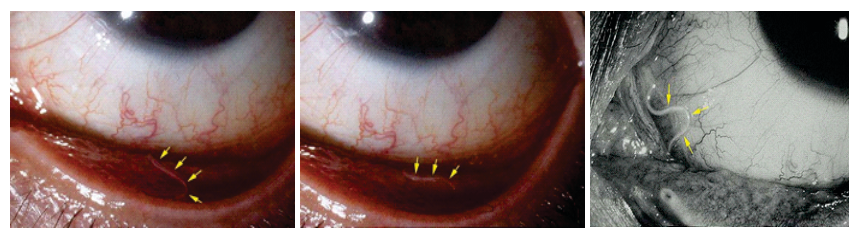

Fig 4. Clinical presentation of ocular thelaziasis ${ }^{50}$ 


\section{Nepal scenario}

In Nepal, the first case of human ocular thelaziasis presented with conjunctivitis was reported in a six month-old child from Rukum district, in 2018. The child was from a poor family, and lived in a village where humans and animals live in close proximity. His mother reported a recent history of an insect (fly) sitting over the medial canthus of the right eye of the baby. ${ }^{21}$

In 2021, the second case reported was an 83-year-old man from a hilly rural region of Nepal who came for his routine glaucoma follow-up was found to harbor six eye worms in the conjunctival fornices. ${ }^{22}$

In the same year, a one and half-year-old female child from Palpa, Nepal was brought to the outpatient ophthalmology clinic after her mother noticed a whitish, thread-like worm in her right eye. A total of four worms were mechanically removed from her right eye. All the collected worms were gravid female nematodes of Thelazia species. $^{23}$

Another case of human ocular thelaziasis was identified as a nematode parasite morphologically resembling $T$. callipaeda at Department of Microbiology, Universal College of Medical Sciences, Bhairahawa, Nepal, from a sample containing parasite, which was removed by viscoelastic surgery at Lumbini Eye Instititue, Bhairahawa, Nepal, in September, 2019. The patient was 53 years old female from Maharajgunj, Uttar Pradesh, India, along Indo-Nepal border, presented with pain and redness in the right eye for three months. This was the first case where the parasite was located in the anterior chamber of eye (intra-ocular thelaziasis) where as in almost all cases of thelaziasis, parasites were found in conjunctival sac, and lachrymal sac. ${ }^{1,4}$

\section{Indian scenario}

A review of literature shows that 14 cases of human ocular Thelaziasis have been reported from India. The first case reported was from Salem, Tamil Nadu, India in $1948 .{ }^{13}$ Subsequently, other cases were reported from various parts of India including Himachal Pradesh, ${ }^{24}$ Manipur, ${ }^{25,26}$ Assam, ${ }^{6,27-29,31}$ Chennai (Tamil Nadu), ${ }^{30}$ Uttar Pradesh, ${ }^{32}$ and Karnataka. ${ }^{33}$

Das JK et al (2018) reported a rare ocular thelaziasis case where live encysted $T$. callipaeda presenting as a lump adjacent to the right lachrymal sac, in a 42-year-old female, farmer and cattle breeder by occupation, presented with swelling, pain, and redness of the right eye. ${ }^{6}$

Kamaldeep Singh (2018) reported a first case of human ocular thelaziasis caused by T. californiensis that was found wiggling in the anterior chamber of the eye, in a 40 -year-old male, with complaint of floaters in left eye. This is the first human case of T. californiensis from India as T. californiensis occurs solely in Western USA. ${ }^{34}$

Tripathi A et al (2020) reported a rare case of human thelaziasis in a 13-year-old female child from Kanpur, India. The patient was able to recover wriggly creatures from her right eye with her bare fingers. The child is from a poor family and lives in an area where humans and animals live close to each other. ${ }^{32}$

Barua Purnima et al (2019) reported a case of thelaziasis in a 36-year-old male, from Majuli, Assam, with a complaint of 'something' inside the left eye since one month. After two days of exploration a small whitish appearing point was seen in deep upper conjunctival cul-de-sac of left eye which was grasped with a forcep and pulled outwards. On further exploration another worm was noticed inside left upper lid in the sub conjunctival space. ${ }^{31}$ Runumi Chowdhury et al (2018) reported a case of ocular thelaziasis from a rural area of Morigaon district of Assam in 2017, that was discovered accidentally during cataract surgery. ${ }^{35}$ Nath et al (2008) recovered small, white, thread-like, motile worms from the conjunctival sac of a 13-year-old girl and a 50-year-old woman from Dibrugarh district, Assam. ${ }^{28}$

\section{Global scenario}

Viriyavejakul P et al (2012) reported a rare case of human thelaziasis in a 31-year-old man from Nakhon Pathom, Thailand presented with a foreign body sensation in and excessive lachrymation from the right eye, with a history of a fly flying around his face, and rubbing it against his right eye. Five adult worms of $T$. callipaeda were collected from the conjunctival sac of the right eye. ${ }^{36}$ Yang YJ et al (2006) observed the occurrence of human thelaziasis in Taiwan and reported a case of 62-year-old woman with unilateral eye swelling and itching, caused by the infestation of $T$. callipaeda. $^{37}$

Woon-Mok Sohn et al (2011) made a brief review of Korean cases and reported two cases of human thelaziasis from with foreign body sensation and itching of the right eye. One case was reported in March 2000 in a 58-year-old woman, and lost the eye sight after ten years in 2010; and another case was in 80 -year-old man acquired during mountain climbing and subsequently undergone treatment and recovered. ${ }^{38}$ Chung Hyuk Yim et al (2016) reported a pediatric case of thelaziasis in Korea in a 6-year-old boy living in an urban area and contracted an ocular infection incidentally during ecological agritainment. ${ }^{39}$ From Vietnam, the first human case of T.callipaeda infection was reported by De NV et al in $2012 .{ }^{40}$

The first case of human thelaziasis from Bangladesh was 
reported by Hossain et al (2011) in a 58-year-old man with itching, redness, foreign body sensation, lachrymation, and filamentary discharge from the right eye. ${ }^{41}$

Otranto D and Dutto M (2008) reported T.callipaeda infection in four patients in Italy and France in the same area where canine thelaziasis had been reported. They emphasized the importance of differential diagnosis of thelaziasis from bacterial or allergic conjunctivitis. ${ }^{42}$ Dutto M (2008) reported a case of human ocular thelaziasis in man in Northern Italy. ${ }^{43}$

\section{DIAGNOSIS}

A definitive diagnosis of thelaziasis is made by detection of the parasites in the conjunctival sac or migrating over the cornea by ophthalmologists. ${ }^{1,6}$ The embryonated eggs or firststage larvae (L1) can be seen when tears or other eye secretions are examined under a microscope. After application of topical anesthetic to eye, worms can be easily removed with forceps and identified by microscopic examination. ${ }^{1,4,6}$ Human T. californiensis infestation should be included in the differential diagnosis of patients with chronic conjunctivitis. ${ }^{34,42}$ T.callipaeda and T. californiensis can be differentiated morphologically based on the numbers of preand post-cloacal papillae in the male worm and position of the vulva in the female worm. ${ }^{4}$ Few studies describe the molecular characterization and phylogeny of Thelazia. ${ }^{1,44}$

\section{TREATMENT}

Thelaziasis can be treated topically by direct application of drugs into the eyes, and by mechanical removal of adult parasites with fine forceps, using local anesthesia. The symptoms usually resolve immediately after removal of the worms. ${ }^{45}$ Irrigation with Lugol's iodine or $2-3 \%$ boric acid is recommended immediately after worm removal or for parasites that are in the lachrymal ducts where they cannot be removed manually. ${ }^{45}$ Pars plana vitrectomy can be used for treatment of patients with an intraocular infestation with $T$. callipaeda. $^{42}$ Levamisole $(2 \mathrm{~mL})$ injection into the conjunctival sac, has been found more effective than orally (5 $\mathrm{mg} / \mathrm{kg}){ }^{46} \quad$ Rossi L et al advocated the application of organophosphates, ${ }^{47}$ Lia RP et al found $1 \%$ moxidectin was effective. ${ }^{48}$ A dose of $2 \mathrm{mg} / \mathrm{kg}$ ivermectin given sub cutaneously has also been shown to cure similar infestations. ${ }^{4,49}$ In addition, antibiotic ophthalmic drops can be given to prevent secondary bacterial infections. ${ }^{4,45}$

\section{PREVENTION}

There is no vaccine for thelaziasis. Thus, prevention of human thelaziasis should include stringent control of the vector flies, use of bed nets, maintaining personal hygiene (particularly by keeping their faces and eyes clean) cleanliness of domestic animals, and treatment of infected domestic animals, and keeping surroundings clean to control the vector population, and public awareness campaign. ${ }^{1,4}$ Also, the prophylactic use of a monthly treatment with milbemycin oxime showed a $90 \%$ efficacy against $T$. callipaeda in naturally exposed dogs. ${ }^{4,49}$ People of rural areas who live in close contact with domestic animals and in unhygienic conditions are at greater risk of human thelaziasis. The concerned authorities and the community should be alerted if eye worms are noticed in domestic animals and humans to take necessary preventive measures, particularly, in some areas, like parts of India where there is a high infestation rate among dogs. ${ }^{22}$

\section{CONCLUSION}

The scientific knowledge on human thelaziosis is still relatively limited, and received little attention, despite the high prevalence recorded in some Asian countries, and represents an alert for both clinicians and general population. ${ }^{19}$ Awareness of this underestimated, emerging and neglected zoonotic parasitic eye disease among ophthalmologists and clinicians is important for timely diagnosis, and to prevent further ocular complications such as blindness, especially in infants who cannot protect themselves from flies. An integration of medical and veterinary expertise is needed to improve scientific knowledge to control this eye worm disease. ${ }^{4,19}$

\section{REFERENCES}

1. Otranto D, Dutto M. Human thelaziasis, Europe. Emerging Infectious Diseases. April 2008;14(4):647-9.

2. Kirschner BI, Dunn JP, Ostler HB. Conjunctivitis caused by Thelazia californiensis. Am J Ophthalmol. Nov 1990;110 (5):573-4.

3. Domenico Otranto, and Filipe Dantas-Torres. Transmission of the eye worm Thelazia callipaeda: between fantasy and reality. Parasites \& Vectors. 2015;8:273.

4. Naem S. Thelazia species and conjunctivitis. In: Pelikan, Z, editors., ed. Conjuctivitis-A Complex and Multifaceted Disorder. Croatia, Europe: INTECH open science/open minds; 2011:201-32, chapter 13 .

5. Amal R. Nimir, Ahmed Saliem, Ibrahim Abdel Aziz Ibrahim. Ophthalmic Parasitosis: A Review Article. Interdisciplinary Perspectives on Infectious Diseases. Volume 2012, Article ID 587402.

6. Das JK, Das D, Deshmukh S, Gupta K, Tomar SS, Borah E, et al. Live encysted Thelazia callipaeda presenting as a lump adjacent to the right lacrimal sac in a 42-year-old female: A rare case report. Indian J Ophthalmol. 2018;66:1220-3.

7. Bradbury RS, Breen KV, Bonura EM, Hoyt JW, Bishop HS. 
Case report- Conjunctival infestation with Thelazia gulosa-a novel agent of human thelaziasis in United States. Am J Trop Med Hyg. 2018;98(4):1171-4.

8. Bhaibulaya M, Prasertsilpa S, Vajrasthira S. Thelazia callipaeda Railliet and Henry 1910, in man and dog in Thailand. Am J Trop Med Hyg. May 1970;19(3):476-9.

9. Chen CC, Zhang YM. A case report of human thelaziosis in the eye anterior chamber. Chinese J Ophthalmol. 1954;4:466.

10. Miroshnichenko VA, Desiaterik MP, Novik AP, Gorbach AP, Papernova Niu. A case of ocular thelaziasis in a 3-year-old child Vestn Oftalmol. 1988;104(2):64.

11. Kosin E, Kosman ML, Depary AA. First case of human Thelaziasis in Indonesia. Southeast Asian J Trop Med Public Health. June 1989;20(2):233-6.

12. Yospaiboon Y, Sithithavorn P, Maleewong V, Ukosanakarn U, Bhaibulaya M. Ocular thelaziasis in Thailand: a case report. J Med Assoc Thai. Aug 1989;72(8):469-73.

13. Friedmann M. Thelazia callipaeda, the oriental eye worm. Antiseptic. 1948;45:620-6.

14. Cheung WK, Lu HJ, Liang CH, Peng ML, Lee HH. Conjunctivitis caused by Thelazia callipaeda infestation in a woman. J Formos Med Assoc. Jun 1998;97(6):425-7.

15. Yang YJ, Liag TH, Lin SH, Chen HC, Lai SC. Human Thelaziasis occurrence in Taiwan. Clin Exp Optom. Jan 2006;89(1):40-4.

16. Koyama Y, Ohira A, Kono T, Yoneyama T, Shiwaku K. Five cases of thelaziasis. Br J Ophthalmol. 2000;84:441.

17. Min HK, Chun KS. A case of human thelaziasis in both eyes. Korean J Parasitol. Jun 1988;26(2):133-5.

18. Ohira A. Five cases of thelaziasis. Br J Ophthalmol. Apr 2000;84(4):441.

19. Shen JL, Gasser RB, Chu D, Wang ZX, Yuan X, Cantacessi C. Human thelaziosis: a neglected parasitic disease of the eye. J Parasitol. Aug 2006;92(4):872-5.

20. Zakir R, Zhong-Xia ZP, Chiodini P, Canning CR. Intraocular infestation with the worm, Thelazia callipaeda. $\mathrm{Br} J$ Ophthalmol. 1999;83(10),1994-5.

21. Ranjit Sah, Sushila Khadka, Mahesh Adhikari, Reema Niraula, Apoorva Shah, Anadi Khatri, and Suzanne Donovan. Human Thelaziasis: Emerging ocular pathogen in Nepal. Open Forum Infect Dis. 2018 Oct;5(10):ofy237.

22. Pokhrel K, Bajracharya L, Bade AR. A case report on eye worm, Thelazia callipaeda, in an elderly person in Nepal. SN Compr. Clin. Med. 2021;3:2024-8.

23. Pal A, Atreya A, Maharjan N, Mahat M, Bom R. Human ocular thelaziasis: A case report. Journal of Nepal Medical Association. 2021;59(242):1060-2.
24. Sharma A, Pandey M, Sharma V, Kanga A, Gupta ML. A case of human thelaziasis from Himachal Pradesh. Indian J Med Microbiol. 2006;24:67-9.

25. Singh TS, Singh KN. Thelaziasis: Report of two cases. Br J Ophthalmol. 1993;77:528-9.

26. Singh RM, Singh HL, Gurumayum P, Gambhir Singh RK. Human ocular thelaziasis: A case report from Manipur, India. Ann Trop Med Public Health. 2015;8:13-5.

27. Mahanta J, Alger J, Bordoloi P. Eye infestation with thelazia species. Indian J Ophthalmol. 1996;44:99-101.

28. Nath R, Narain K, Saikia L, Pujari BS, Thakuria B, Mahanta J, et al. Ocular thelaziasis in Assam: A report of two cases. Indian J Pathol Microbiol. 2008;51:146-8.

29. Handique AK, Tamuli A, Khan AM. Ocular thelaziasis in a 7month-old infant. Indian J Med Microbiol. 2014;32:84-6.

30. Rathinasamy M, Subhadevi S. Ocular thelaziasis in a 4 months old girl child. Chettinad Health City Med J. 2014;3:15-7.

31. Barua Purnima, Ubed Parveez, Das Angshurekha, Borkotoki Uttara. Thelaziasis: an emerging ocular parasite in Northeast of India. Int J Health Res Medico Leg Prae. 2019 January;5(1):72 4.

32. Tripathi A, Bhalla S. Wriggly creatures coming out of eye: case report on human ocular thelaziasis. Trop J Ophthalmol Otolaryngol. 2020;5(8):250-3.

33. Krishnachary PS, Shankarappa VG, Rajarathnam R, Shanthappa M. Human ocular thelaziasis in Karnataka Indian Journal of Ophthalmology. July 2014;62(7):822-4.

34. Dr Kamaldeep Singh, Dr Ashish Khindria. First case of human ocular thelaziasis from India caused by Thelazia californiensis: A case report. IOSR Journal of Dental and Medical Sciences (IOSR-JDMS). 2018;17(1):24-27.

35. Runumi Chowdhury, Mayuri Gogoi, Anjan Sarma, Ajanta Sharma. Ocular thelaziasis: A case report from Assam, India Trop Parasitol. 2018 Jul-Dec; 8(2): 94-7.

36. Viriyavejakul P, Krudsood S, Monkhonmu S, Punsawad C, Riganti M, Radomyos P. Thelazia callipaeda-a human case report. Southeast Asian J Trop Med Public Health 2012;43(4):851-6

37. Yang YJ, Liag TH, Lin SH, Chen HC, Lai SC. Human thelaziosis occurrence in Taiwan. Clinical and Experimental Optometry. 2006;89(1):40-44.

38. Woon-Mok Sohn, Byoung-Kuk Na, Ji Myong Yoo. Two cases of human thelaziasis and brief review of Korean cases. Korean J Parasitol. September 2011;49(3):265-271.

39. Chung Hyuk Yim, Jeong Hee Ko, Jung Hyun Lee, Yu Mi Choi, Won Wook Lee1, Sang Ki Ahn, Myoung Hee Ahn, Kyong Eun Choi. A Pediatric Case of Thelaziasis in Korea. Korean J 
Parasitol. June 2016;54(3): 319-321.

40. De NV, Le TH, Chai JY. The first human case of Thelazia callipaeda infection in Vietnam. Korean J Parasitol. 2012;5093):221-3.

41. Hossain MI, Hossain, MA, Nahar L, Hossain MM, Mondal AS, Alim MA, Mahmud MC, Islam A. Human thelaziasis in Bangladesh. Mymensingh Med J. 2011;20(1):128-130.

42. Otranto D, Dutto M. Human thelaziasis, Europe. Emerging Infectious Diseases. www.cdc.gov/eid. 2008; 14(4): 647-8.

43. Dutto M. Ocular thelaziasis in man in Northern Italy. Bull Soc Pathol Exot. 2008;101(1):9-10.

44. Nadler S, Hoberg EP, Hudspeth DS, Rickard LG. Relationships of Nematodirus species and Nematodirus battus isolates (Nematoda: Trichostrongyloidea) based on nuclear ribosomal DNA sequences. J Parasitol. June 2000;86(3):588-601.

45. Wang KC, Wang ZX, Shen JL. Canine infection with Thelazia callipaeda and human thelaziosis. J Trop Dis Parasitol. 1999;28:216-8.

46. Michalski I. The efficacy of levamisole and tetramisole in the treatment of thelaziasis in cattle. Med Weter, 1976;32:417-9.

47. Rossi L, Peruccio C. Thelaziosi oculare nel Cane: Aspetti clinici e terapeutici. Veterinaria. 1989;2:47-50

48. Lia RP, Traversa D, Agostini A, Otranto D. Field efficacy of moxidectin 1 per cent against Thelazia callipaeda in naturally infected dogs. Vet Rec. Jan 2004;154(5):143-5.

49. Valentina Marino, Rosa Gálvez, Carmen Mascuñán, Inés Domínguez, Juliana Sarquis, Ana Montoya, et al. Update on the treatment and prevention of ocular thelaziosis (Thelazia callipaeda) in naturally infected dogs from Spain. International Journal for Parasitology. 2021;51:73-81.

50. Elizabeth Dorfman. Human Biology 103. Images from the University of Pittsburgh Medical Center. Parasites and Pestilence: Infectious Public Health Challenges. Stanford University.

51. Otranto D, Mendoza-Roldan JA, Dantas-Torres F. Trends in Parasitology. 2021;37(3):263-4. 